\title{
Sensitivity of Coastal Currents near Point Conception to Forcing by Three Different Winds: ECMWF, COAMPS, and Blended SSM/I-ECMWF-Buoy Winds
}

\author{
Changming Dong And Lie-Yauw Oey \\ Program in Atmospheric and Oceanic Sciences, Princeton University, Princeton, New Jersey
}

(Manuscript received 16 January 2004, in final form 10 September 2004)

\begin{abstract}
Previous observational and modeling studies have indicated the importance of finescale winds in determining the circulation near Point Conception in the Santa Maria Basin (SMB) and the Santa Barbara Channel (SBC), California. There has not been a systematic attempt, however, to analyze and quantify the sensitivity of the near-surface circulation to different wind data. Here, a regional circulation model of the SMB and SBC is driven using three wind datasets: the European Centre for Medium-Range Weather Forecasts $(\mathrm{ECMWF} ; \approx 110 \mathrm{~km} \times 110 \mathrm{~km}$ horizontal grid), the Coupled Ocean-Atmosphere Mesoscale Prediction System (COAMPS; $9 \mathrm{~km} \times 9 \mathrm{~km}$ horizontal grid), and a blended wind product that combines Special Sensor Microwave Imager (SSM/I), ECMWF, and buoy and coastal wind data and that is referred to as SEB. A springtime period (March-May 1999) in which equatorward wind dominates and wind stress curls are strong is chosen for the study. Two groups of experiments are conducted: with and without assimilating moored temperature observations. The focus is on long time scales of greater than weeks and on mean currents. Comparisons between these experiments and between model and observation show that the circulation driven by the ECMWF wind is much weaker than that by the other two winds. On the other hand, the SEB dataset shows locally intensified wind stress curls behind capes and coastal bends, whereas these wind stress curls are weak in COAMPS. It is found that these small-scale variations in the wind field force alongshore inhomogeneous pressure gradients that in turn can significantly affect the near-coast currents. The result is that modeled currents forced by SEB agree better with observations than do those produced by COAMPS. Empirical orthogonal function analyses were conducted on the near-surface currents, sea level, wind, and wind stress curl. The mode- 1 current $(\approx 40 \%)$ is unidirectional (i.e., generally equatorward or poleward) and correlates well with the mode- 1 wind $(\approx 90 \%)$. The mode- 2 current $(\approx 20 \%)$ is cyclonic in the SBC and poleward inshore and equatorward offshore in the SMB; it correlates well with mode-1 sea level $(\approx 70 \%$ ), which suggests that mode- 2 currents are driven by the pressure gradient. It is significant that neither mode- 2 current nor mode- 1 sea level correlates well with mode- 1 wind stress curl $(\approx 70 \%)$; rather, they correlate well with the time integral of the mode- 1 wind stress curl. These conclusions support a previous theoretical idea that cyclonic circulation in the SBC and the inshore currents of the SMB are both driven by alongshore pressure setup induced by the time integral of the wind stress curl, rather than by the wind stress curl itself. This idea of a pressure setup is consistent with the differences found between the currents driven by COAMPS and SEB winds.
\end{abstract}

\section{Introduction}

The importance of wind stress and wind curl to the near-surface circulation near Point Conception, the Santa Barbara Channel (SBC), and Santa Maria Basin (SMB), California (see Fig. 1), is now well documented (Oey 1996, 1999; Wang 1997; Harms and Winant 1998).

Corresponding author address: Lie-Yauw Oey, Program in Atmospheric and Oceanic Sciences, Sayre Hall, Princeton University, Princeton, NJ 08544.

E-mail: lyo@princeton.edu
Harms and Winant (1998) showed that surface currents depend on the wind stress and (alongshore) pressure gradients in the SBC. The alongshore gradient of wind curl may build up a pressure gradient against the wind direction and can force a poleward current nearshore when the wind relaxes (Oey 1996, 1999; Wang 1997). Winant et al. (2003) further studied the seasonal variation of the circulation and categorized it into three patterns: upwelling (spring), convergence (summer), and relaxation (fall and winter). These studies suggest that near-surface currents in SBC and SMB are sensitive to wind. 


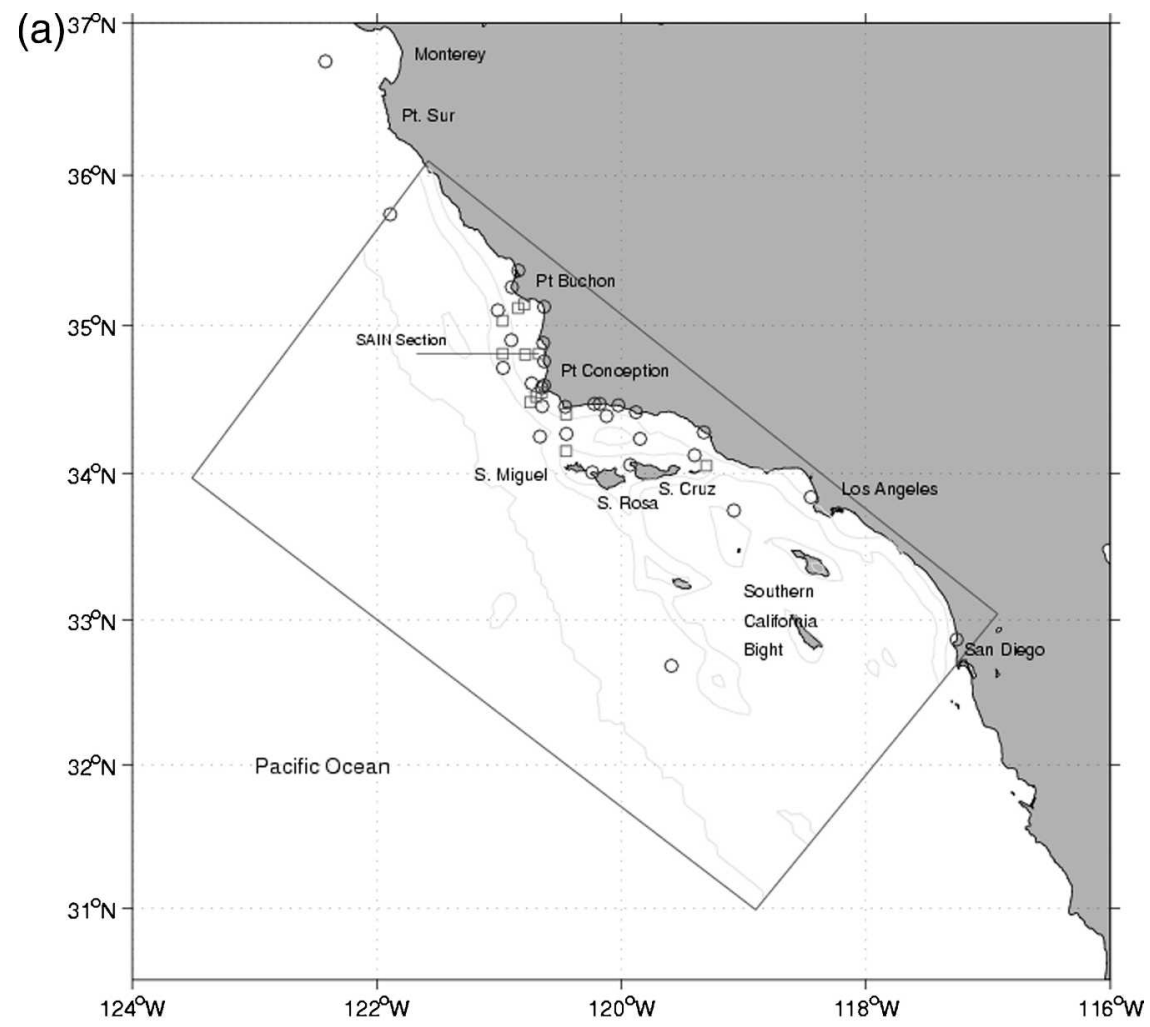

(b)

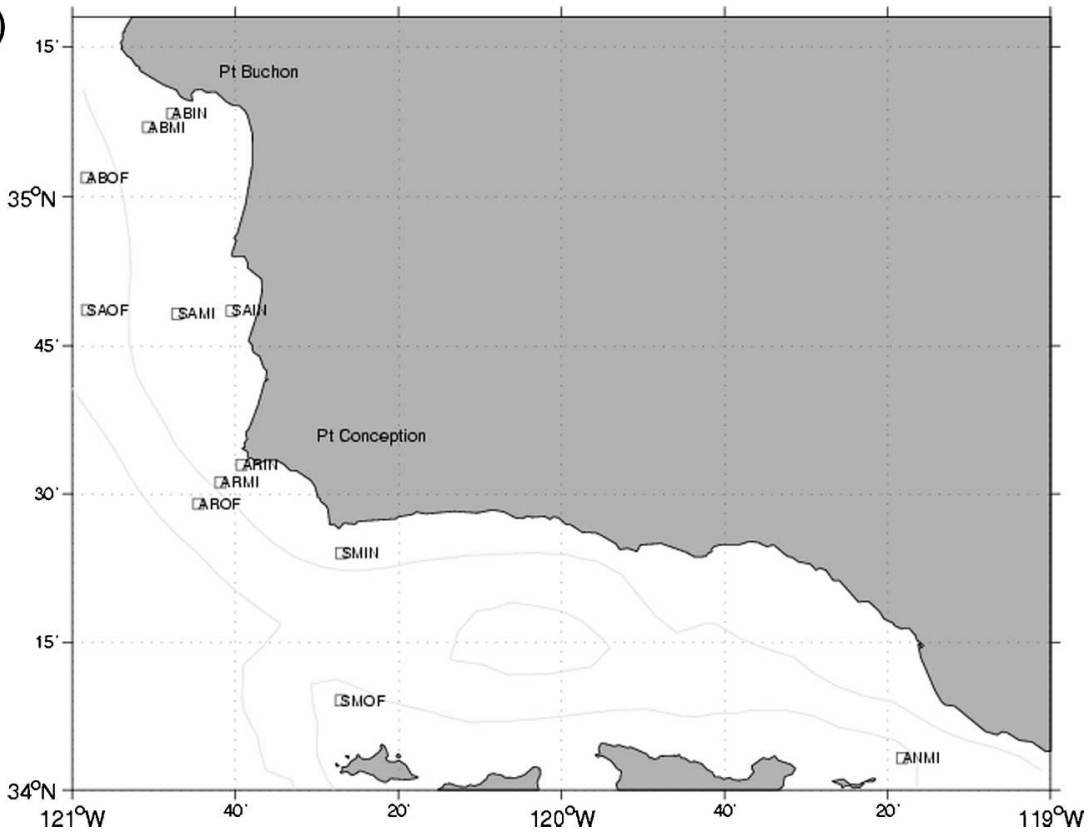

FIG. 1. (a) A locator map of the ocean region of interest. The rectangle is the ocean model domain. Light contours denote the 200-, 500-, and 2000-m isobaths. Circles denote the 32 meteorological stations (for wind data), and squares denote the 12 mooring stations for temperature and current data. (b) The locations and names of the 12 mooring stations.

The seasonal variation of wind in the SMB and SBC is described in detail by Dorman and Winant (2000). In spring and summer, winds become persistently equatorward and intensified west of the SBC but diminish toward the east. Based on the California Cooperative Fishery Investigation (CalCOFI) ship wind data, Winant and Dorman (1997) divided the wind stress in spring and summer into two regions: a high-wind zone 
in the area offshore from a line between Point Conception and Ensenada, Mexico, and a low-wind zone inshore of the line. They showed the sharp local change in the wind stress and wind stress curl: high-wind zone extends throughout the entire offshore region west and south of the SBC and the maximum wind stress and maximum wind stress curl are located off Point Conception. The wind variation scale is about $10-30 \mathrm{~km}$. To incorporate the sharp change in wind stress and wind stress curl, a high-resolution wind is needed for the simulation of the circulation in this region.

In a previous numerical simulation of the circulation in SBC and SMB (Oey et al. 2004), the wind used to drive the ocean is a combination of the European Centre for Medium-Range Weather Forecasts (ECMWF) wind (which has a coarse resolution of about $1.125^{\circ}$ ) and local meteorological stations by optimum interpolation (OI). Oey et al.'s work shows that the circulation forced by the wind captures the cyclonic circulation in the western part of the SBC and its seasonal variation. By incorporating wind data from coastal stations with ECMWF wind, Oey et al. (2004) show that the modeled circulation is in better agreement with observations than that forced by the coarse-grid ECMWF wind only. In this paper, we extend the work of Oey et al. and examine more closely the sensitivity of the ocean currents to forcing by different wind datasets. Apart from the ECMWF, two higher-resolution wind datasets are used in this work.

Dong et al. (2003) produced a new wind dataset in SMB and SBC by combining three wind datasets: the Special Sensor Microwave Imager (SSM/I) wind data from satellite remote sensing, ECMWF wind, and wind data from 32 buoy and other coastal wind stations (marked as circles in Fig. 1) deployed by the National Data Buoy Center (NDBC) and the Minerals Management Service. Dong et al. (2003) found that the ECMWF wind agreed well with offshore $(\approx 50 \mathrm{~km}$ and more from the coast) buoy wind data. However, the ECMWF speeds are weaker than buoy data, especially near the coast. The ECMWF wind directions were therefore retained while its speeds were replaced by SSM/I speeds after the latter have been cleaned and edited for errors. An OI scheme was then used to merge this ECMWF-SSM/I composite dataset with wind data from NDBC buoys and other coastal meteorological stations. The blended wind is hereinafter referred to as the SEB (for SSM/I, ECMWF, and buoy) wind; it is 6-hourly on a $5 \mathrm{~km} \times 5 \mathrm{~km}$ grid covering the rectangular ocean model domain shown in Fig. 1a. The OI scheme is such that the SEB wind reproduces the buoy wind time series at the buoy stations during periods when the observation is available.
In 2003 H.-M. Hsu et al. (unpublished manuscript) used the U.S. Navy's nested-grid regional model, the Coupled Ocean-Atmosphere Mesoscale Prediction System (COAMPS), to produce wind for the period 1 March-31 May 1999. The innermost nest includes the SMB and SBC and has a horizontal resolution of $9 \mathrm{~km}$ $\times 9 \mathrm{~km}$. The simulated winds were found to agree well with buoy observations, especially offshore in the western portion of the SBC and SMB. The results deteriorate in the eastern SBC and very near the coast $(\sim 10$ $\mathrm{km})$. The authors suggest that the $9-\mathrm{km}$ resolution is still insufficient to resolve sharp changes in coastal topography and to simulate hydraulic jumps that often occur in the eastern SBC (Dorman and Winant 2000). The COAMPS wind is also sampled 6-hourly and interpolated onto the same $5 \mathrm{~km} \times 5 \mathrm{~km}$ SEB (or ocean model) grid.

In this study, we examine long-period (weeksmonths) responses of the near-surface circulation to the SEB, COAMPS, and ECMWF winds during the period 1 March-31 May 1999. We study the sensitivity of the near-surface (mean) currents to the wind stress and its small-scale features in the SMB and SBC. During the study period, the region is characterized by a transition to more persistent upwelling-favorable wind in the SMB and a strong wind stress curl in the SBC. Because wind stress curls reveal smaller-scale variations in the wind field, it is necessary that higher resolution and high-quality winds (as outlined above) are used in the ocean modeling and also in analysis.

The paper is organized as follows. In section 2, the SEB, COAMPS, and ECMWF winds are compared. In section 3, the model configuration and numerical experiments are described. In section 4, numerical experiments are compared with each other and with observations. In section 5, empirical orthogonal function (EOF) analysis is presented. Section 6 is discussion and summary.

\section{Wind data}

Figure 2 shows the 3-month-averaged (March-May 1999) wind stress (Fig. 2a) and wind stress curl (Fig. 2b) for the three wind datasets: ECMWF, COAMPS, and SEB. (In this and the following maps, a more detailed subregion of the model domain encompassing the SMB and SBC is shown.) The general directions of the three winds are similar. The ECMWF wind is much weaker than COAMPS and SEB winds, especially near the shore. This result may be attributed to the coarse resolution used in the ECMWF wind. Small-scale variations are smoothed out in the ECMWF wind, and the corresponding wind stress curls are also weaker than the other two winds. The strengths and directions of 

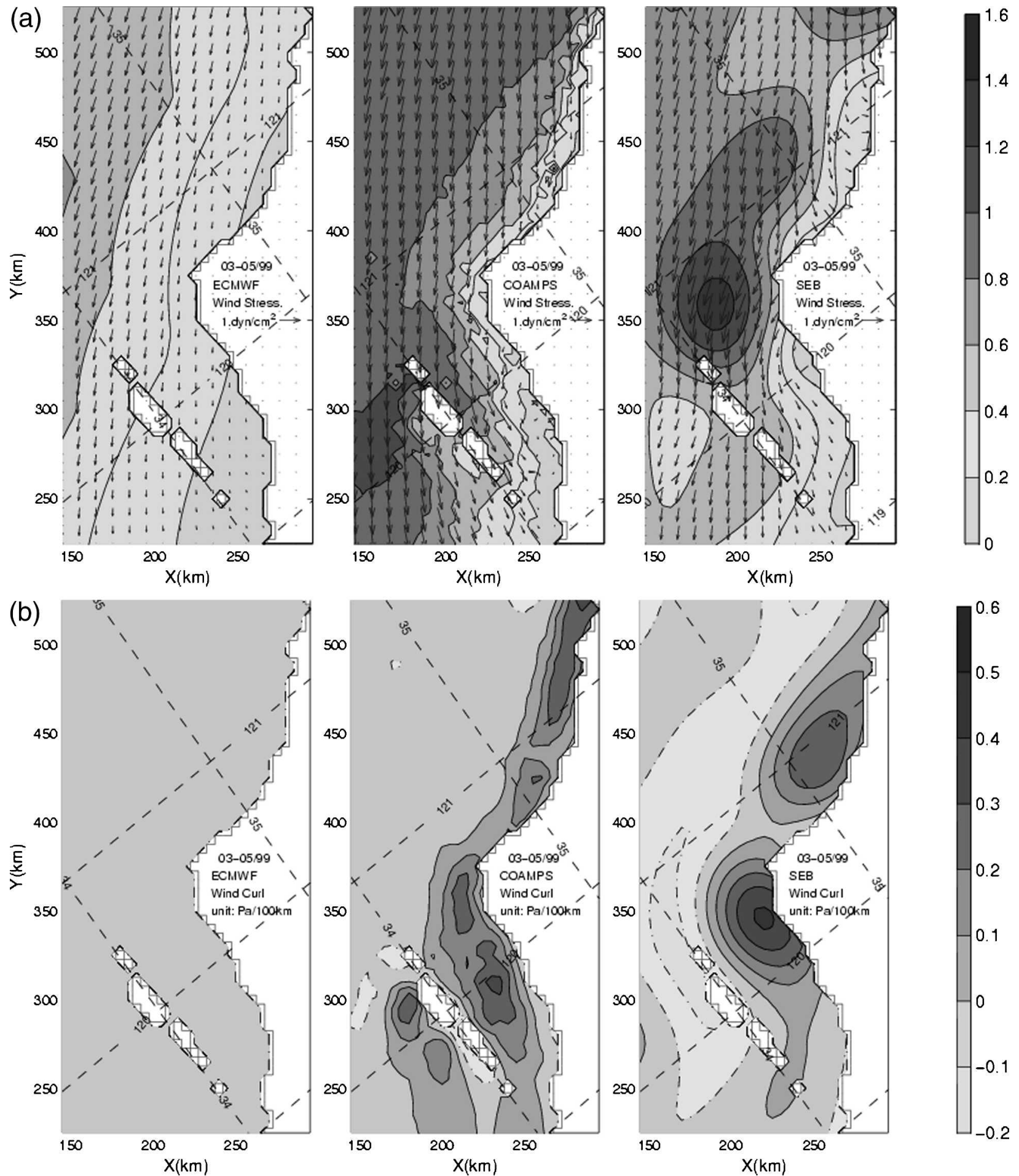

FIG. 2. (a) The 3-month mean wind stress vectors obtained from (left) ECMWF, (middle) COAMPS, and (right) SEB. Contours indicate wind stress magnitudes, and the contour interval is $0.2 \mathrm{dyn} \mathrm{cm}^{-2}$. (b) The 3 -month mean contours of the wind stress curl for (left) ECMWF, (middle) COAMPS, and (right) SEB. The contour interval is $0.2 \mathrm{~Pa}(100 \mathrm{~km})^{-1}$. 
COAMPS and SEB winds are similar. Both show strong equatorward winds over the SMB and west of SBC and rapid weakening eastward into the SBC. The SEB wind shows localized strong speeds approximately $30 \mathrm{~km}$ offshore in the SMB and also in the western SBC. No such localized strong speeds exist in the COAMPS wind. Instead, the COAMPS wind is more uniform alongshore. Differences can be seen clearly in the corresponding wind stress curls (Fig. 2b). The ECMWF wind stress curl is weak-less than $0.1 \mathrm{~Pa}(100$ $\mathrm{km})^{-1}$ throughout the region. COAMPS gives strong wind stress curl near the shore and cells of localized maxima along the coast with values that reach $0.3-0.4$ $\mathrm{Pa}(100 \mathrm{~km})^{-1}$. The SEB wind stress curl near the shore is also strong, but there are two well-organized localized maxima: one downwind of Point Buchon [values $\approx 0.3-0.4 \mathrm{~Pa}(100 \mathrm{~km})^{-1}$ and another one downwind of Point Conception [values $\approx 0.5 \mathrm{~Pa}(100 \mathrm{~km})^{-1}$ ]. The SEB wind also shows an alongshore band of negative curl (albeit weak) at approximately $50 \mathrm{~km}$ offshore. These SEB wind features (localized maximum wind stress curls behind capes and band of negative curl offshore) are known in observations (C. E. Dorman 2003, personal communication). We now show that these subtle differences in wind and wind stress curl have important consequences to the nearshore circulation.

\section{Model configuration and experiments}

\section{a. Model configuration}

The model is based on the Princeton Oceanic Model (Mellor 2002), and its configuration is identical to that used by Oey et al. $(2001,2004)$ in their study of the dynamics of cyclonic circulation and upwelling in the Santa Barbara Channel. Here we briefly describe it. The model grid extends $300 \mathrm{~km}$ offshore and $550 \mathrm{~km}$ in the alongshore direction (Fig. 1a). The horizontal grid resolution is constant, $\Delta x=\Delta y=5 \mathrm{~km}$. The grid is rectangular, and axes have been rotated $52^{\circ}$ anticlockwise. The vertical grid consists of 30 equally spaced sigma levels. The western boundary condition consists of a radiation condition with a sponge layer, within which the horizontal viscosity is linearly increased to 10 times its interior value within 10 grids. The sponge layer damps westward-propagating Rossby waves and helps to prevent the development of an artificial boundary layer. The northern and southern boundary conditions are also radiation with sponge layers. Normal fluxes are zero across all closed boundaries. Across open boundaries, temperature and salinity are advected during outflow and specified using monthly climatological data at inflow. Climatological temperature and salinity are also used for initial conditions (Levitus 1982, 1994).
TABLE 1 . A summary of the numerical experiments.

\begin{tabular}{clc}
\hline \hline Expts & Wind & Assimilation $(T)$ \\
\hline 1 & ECMWF & No \\
2 & COAMPS & No \\
3 & SEB & No \\
$1 \mathrm{a}$ & ECMWF & Yes \\
$2 \mathrm{a}$ & COAMPS & Yes \\
$3 \mathrm{a}$ & SEB & Yes \\
\hline
\end{tabular}

\section{b. Numerical experiments}

As part of a more extensive modeling study (C. Dong and L.-Y. Oey, unpublished manuscript), the SEB wind was used to force the model ocean from a rest state starting on 1 January 1992 and integrated through 1999. For the present study, the initial condition is the model ocean state at the end of February of 1999. A series of numerical experiments are performed with the three winds. Each integration is for 3 months: March-May 1999. These experiments are divided into two groups: without and with temperature assimilation. As in Oey et al. (2004), the temperature assimilation uses the statistical interpolation method (Daley 1993; Chen and Wang 1999, 2000). Temperatures at 12 mooring stations are used in the assimilation; these stations are marked by the square symbols in Figs. 1a,b. Details of the observations are given by Harms and Winant (1998) and Winant et al. (2003). The experiments are summarized in Table 1.

\section{Experiment results}

\section{a. Wind-only experiments 1, 2, and 3}

The mean near-surface currents (at $z=-5 \mathrm{~m}$ ) and sea surface height (SSH) for the wind-only experiments are shown in Figs. 3a and 3b, respectively. Here and in subsequent analyses, the mean (or analysis period) is taken as the average over the period from 10 March to 31 May, thus excluding a 10-day (1-10 March) initial adjustment of the model dynamics to wind. Superimposed on the model current maps are also mean observed currents (heavy vectors; also at $z=-5 \mathrm{~m}$ ) for the same period. The figures show two primary circulation features: a southward flow in the SMB and cyclonic circulation in the western part of the SBC. The nearshore upwelling in the SMB and the upwelling in the cyclonic circulation in the western $\mathrm{SBC}$ show up as lows in the SSH contours in Fig. 3b. It is clear that currents driven by the ECMWF wind (expt 1) are weaker than those driven by the COAMPS wind (expt 2) or the SEB wind (expt 3). As discussed previously, the ECMWF wind is the weakest among the three winds and its resolution near the coast is not sufficient to resolve small-scale wind structures (Fig. 2). In ex- 

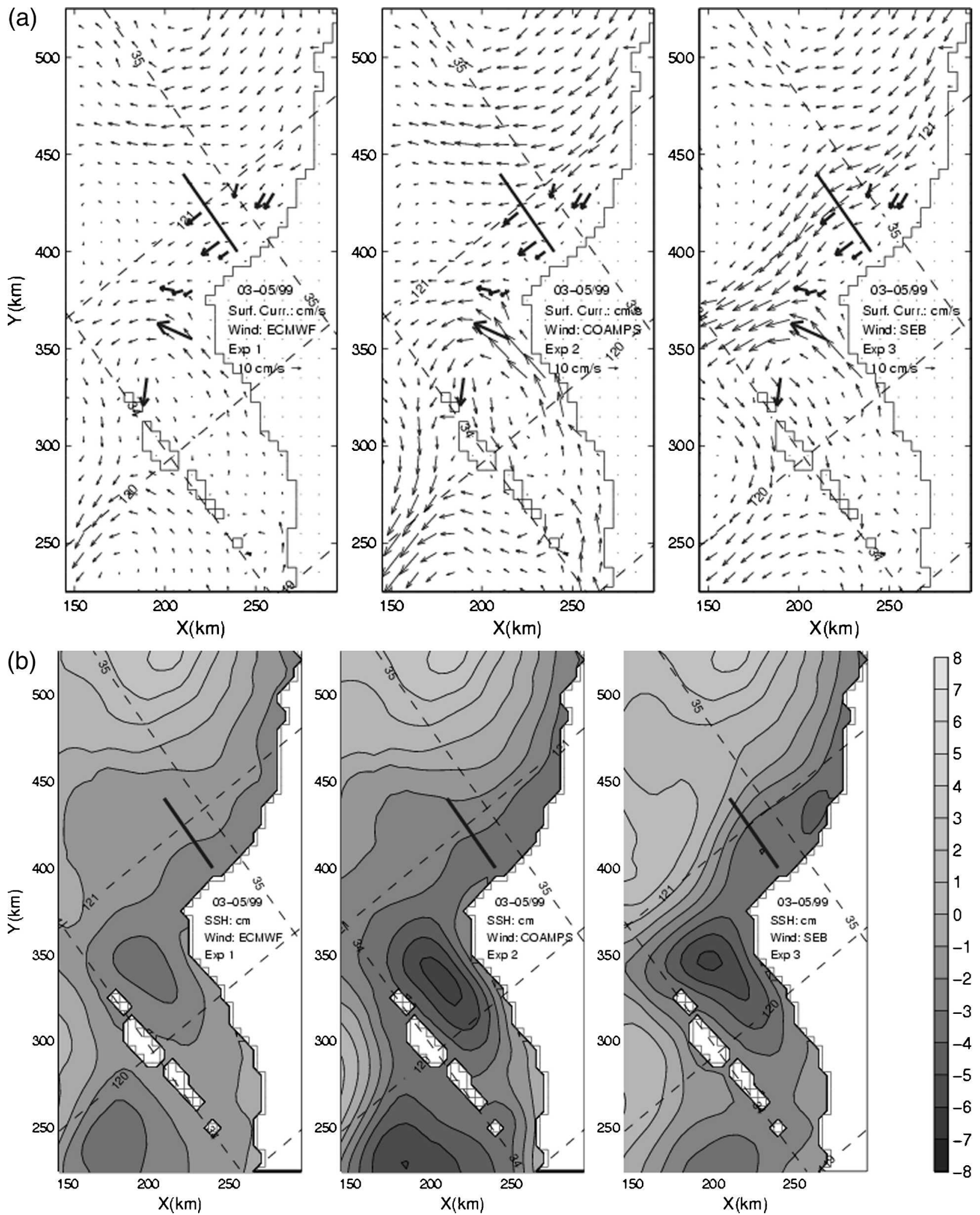

FIG. 3. (a) The 3-month mean currents at $z=-5 \mathrm{~m}$ for wind-only experiments: (left) expt 1 , (middle) expt 2, and (right) expt 3 . The heavy solid vectors are the observed mean currents (also at $z=-5 \mathrm{~m}$ ) at the 12 mooring stations. The solid line is the SAIN section. (b) The 3-month mean sea surface elevation for wind-only experiments: (left) expt 1, (middle) expt 2, and (right) expt 3 . The contour interval is $1 \mathrm{~cm}$. 

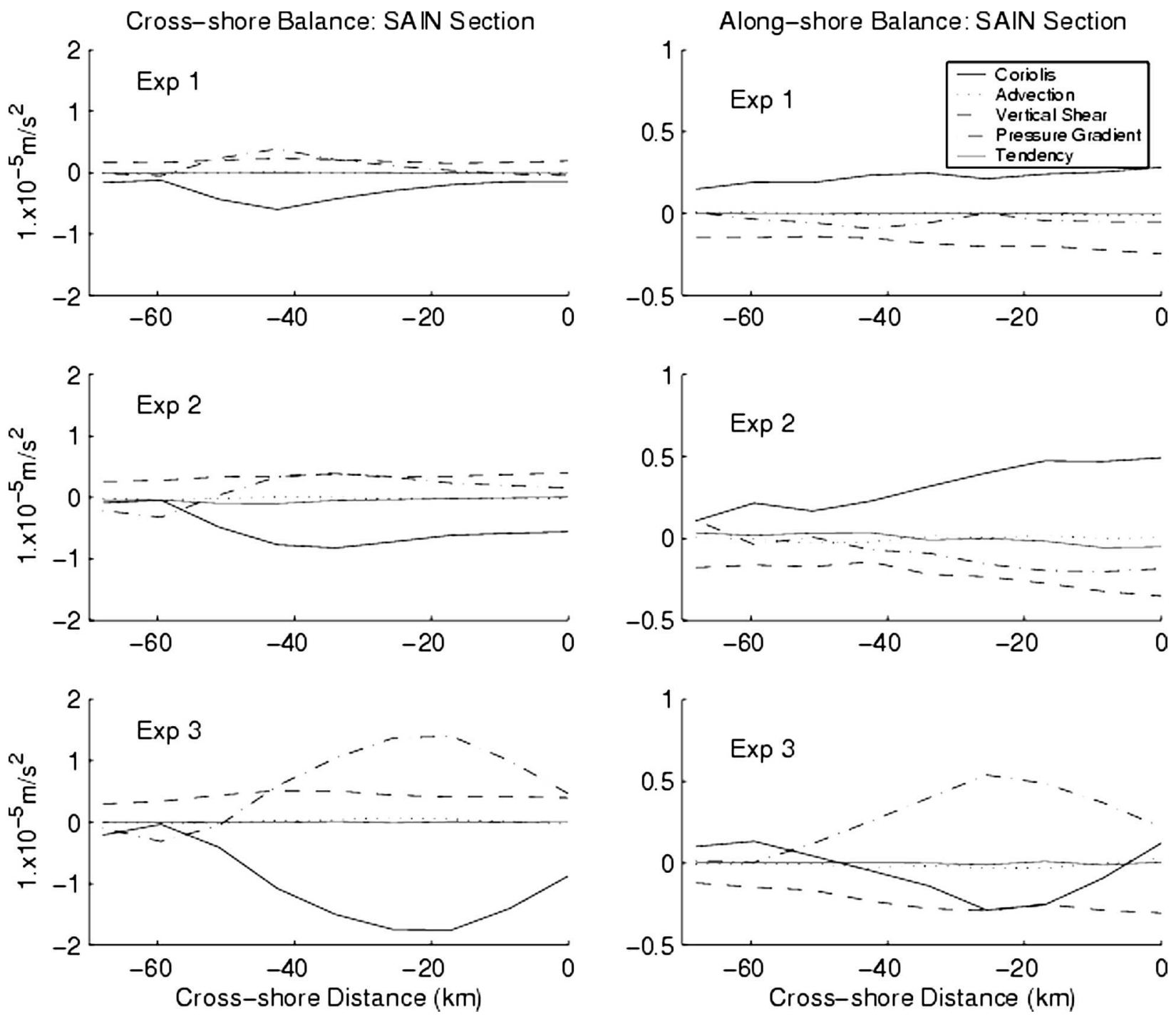

FIG. 4. (left) Cross-shore ( $x=0$ at coast) and (right) alongshore $(y)$ momentum balances at the cross section SAIN (indicated in Figs. 1 and 3 ) for (top) expt 1, (middle) expt 2, and (bottom) expt 3.

periment 3, there are two localized upwelling centers: one off Point Buchon and the other, stronger one off Point Conception. These correspond to the two local maxima in the wind stress curl seen in Fig. 2b. By contrast, experiments 1 and 2 show only one upwelling center in the SBC. In experiment 1, the upwelling is weak. In experiment 2 , the upwelling is strong and extends farther east into the channel. In the SMB, the mean near-surface currents driven by both ECMWF (expt 1) and COAMPS (expt 2) veer offshore near $35^{\circ} \mathrm{N}$, whereas currents driven by the SEB wind (expt 3 ) are more intense and more aligned with the coast. This alongshore alignment of the currents (for expt 3) in the SMB agrees better with the observed currents (Fig. 3a).

The above differences in the circulation pattern can be understood by examining the momentum balance. Figure 4 shows the mean momentum balance in both the alongshore and cross-shore directions at the section SAIN in the SMB (marked as a solid line in Figs. 1 and 3 ) for the three experiments. The balance is primarily among the wind stress (dash; in strict terms, it is the vertical divergence of vertical shear stress; near the surface the term is dominated by the wind stress; cf. Oey et al. 2004), pressure gradient (dash-dot), and Coriolis term (solid). Tendency and advection are small. The cross-shore balance for the three experiments is similar near the coast: the offshore Coriolis force (due to equatorward alongshore current) is balanced by the onshore wind stress and pressure gradient. In experiment 3 , the balance is primarily geostrophic, $f v \approx(\partial p / \partial x) / \rho_{0}$, especially within about $40 \mathrm{~km}$ of the coast; in experiments 1 
(a)

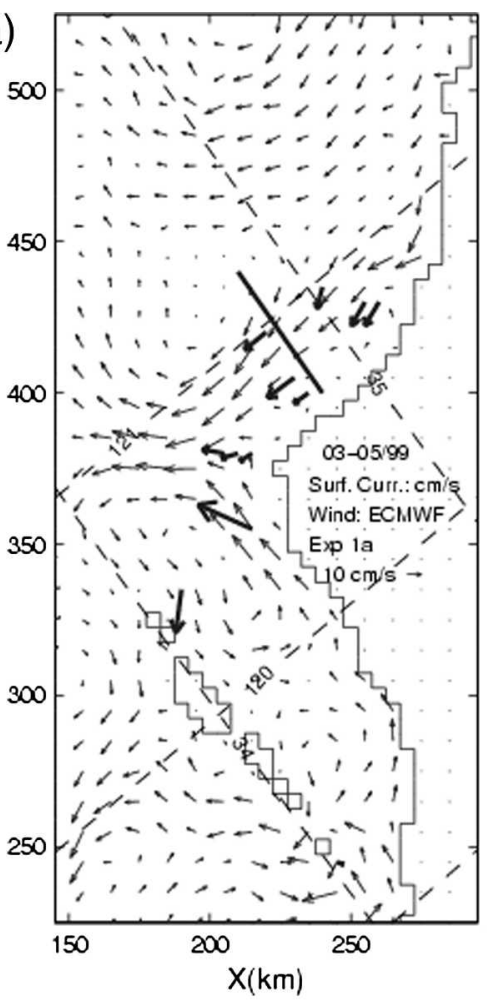

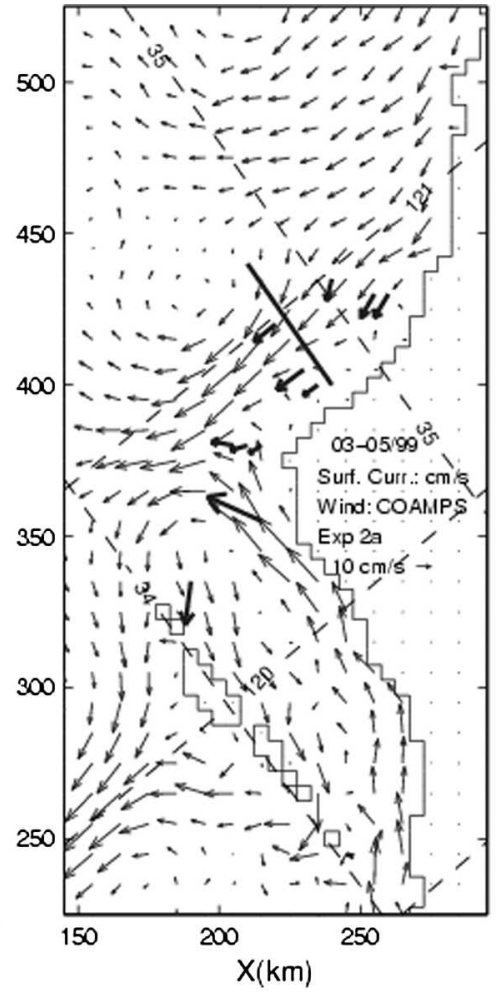

(b)
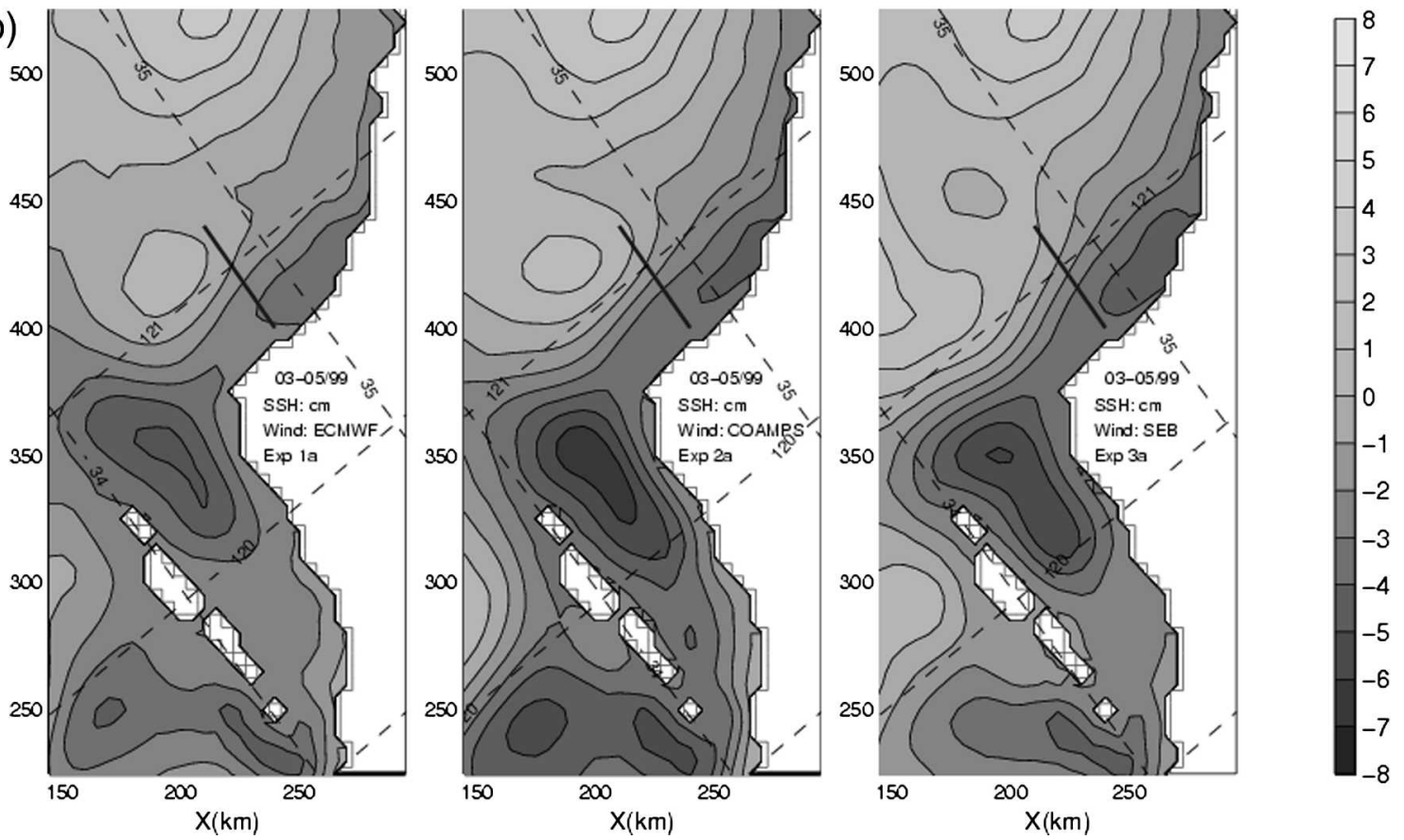

FIG. 5. Same as Fig. 3, but for the experiments with data (temperature) assimilation.

and $2,(\partial p / \partial x) / \rho_{0}$ is weaker and the wind stress term becomes relatively more important. Here, $x$ and $y$ are positive onshore and poleward along the shore, respectively, and the other symbols are standard. In the alongshore direction, momentum balances for the three ex- periments are different. The wind stress term is equatorward for all three experiments. The Coriolis term is directed poleward in experiments 1 and 2, but in experiment 3 it changes sign from poleward offshore to become equatorward within $40 \mathrm{~km}$ of the coast. The 

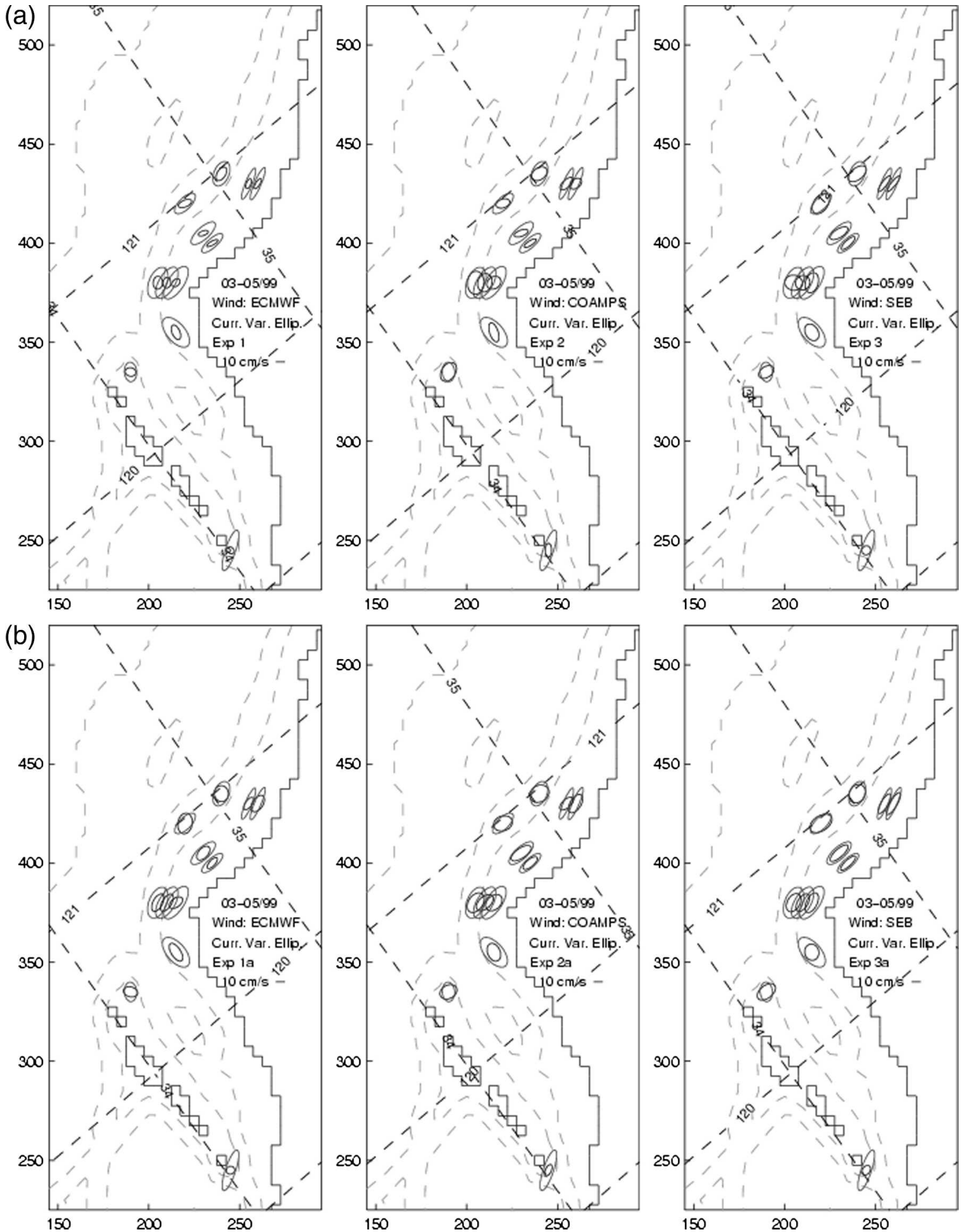

FIG. 6. Comparisons of the surface current variances between model (darker ellipses) and observations (light ellipses) at $5 \mathrm{~m}$ for (a) the wind-only experiments and (b) the experiments with data (temperature) assimilation: (left) ECMWF, (middle) COAMPS, and (right) SEB. Contours are isobaths: 200, 500, and $2000 \mathrm{~m}$. 

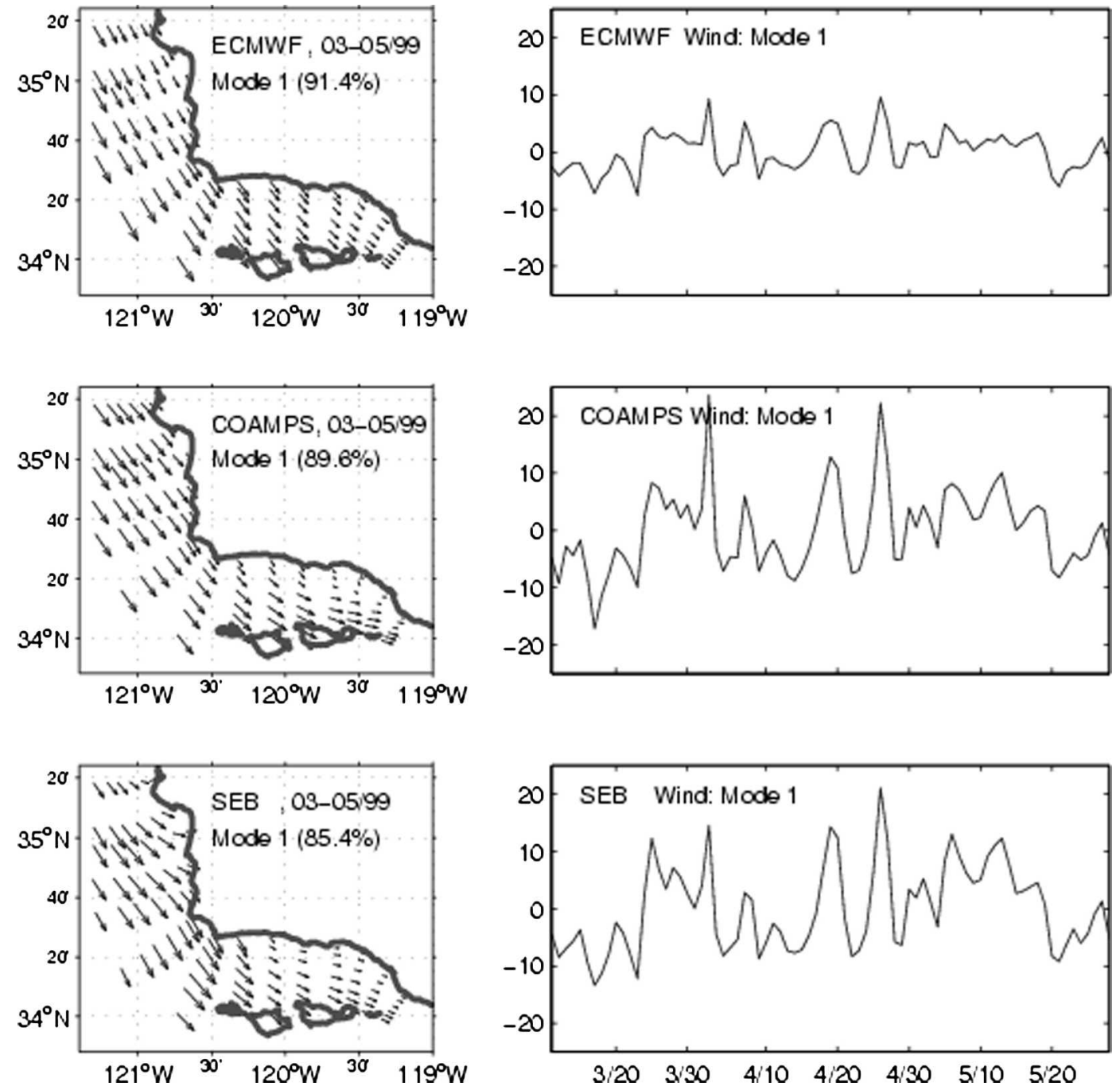

FIG. 7. EOF analysis for wind: (left) the spatial pattern of the first mode and (right) the time series of the first mode for (top) ECMWF, (middle) COAMPS, and (bottom) SEB winds.

pressure gradient is equatorward in experiments 1 and 2 but is poleward and large in experiment 3 . Figure $3 \mathrm{~b}$ indicates that the poleward pressure gradient in experiment 3 is caused by the low (upwelling) center just south of Point Buchon. This pressure gradient overcomes equatorward wind stress in producing onshore flow with equatorward Coriolis component. The onshore convergence helps to maintain the equatorward jet south of $35^{\circ} \mathrm{N}$, as seen in Fig. 3a for experiment 3. In contrast, no localized upwelling center south of Point Buchon exists for experiments 1 or 2. The corresponding pressure gradient is equatorward, which, together with the equatorward wind stress, produces offshore flow. As a result, the coastal jets in experiments 1 and 2 are less well defined as the currents tend to veer offshore south of $35^{\circ} \mathrm{N}$ (Fig. 3a). Considering that the alongshore pressure gradient in part comes from the wind curl and its spatial variation (Oey 1999), the above differences clearly show the subtle sensitivity of coastal currents to wind and wind stress curl along the coast.

\section{b. With temperature assimilation: Experiments 1a, $2 a$, and $3 a$}

For experiments with temperature assimilation, the 3-month-averaged near-surface currents and SSH are plotted in Figs. 5a and 5b, respectively. As compared with the results without assimilation (Fig. 3), the nearsurface currents in the SMB for experiments 1a and 2a now become more intensely equatorward and more aligned with the coast, in better agreement with the observed currents, and also with experiment 3 . The adjustment in experiment $3 \mathrm{a}$ is less, but currents near the coast improve (become somewhat stronger). We con- 

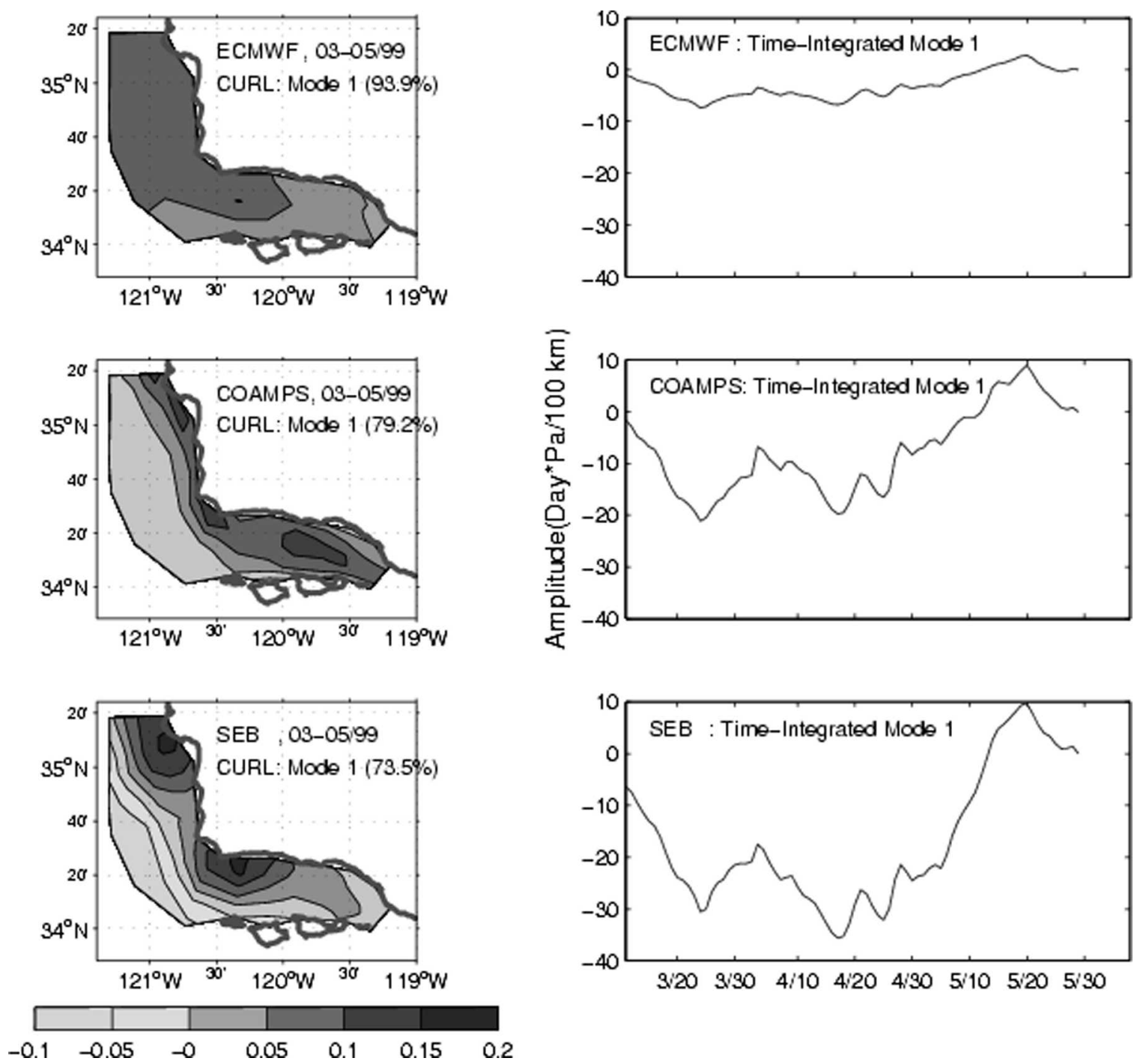

FIG. 8. EOF analysis for wind stress curl: (left) the spatial pattern of the first mode and (right) the time-integrated time series of the first mode of the wind stress curl for (top) ECMWF, (middle) COAMPS, and (bottom) SEB winds.

clude that data assimilation "corrects" deficiency in model physics and forcing (wind; in expts 1 and 2 in particular) and adjusts the modeled currents toward observations. The correction can be seen in the SSH plot in Fig. 5b. Comparing with Fig. 3b, we see that assimilation alters the pressure field such that experiments 1 and 2 now show SSH lows downwind of Point Buchon (the corresponding low for expt 3 is also strengthened), and the SSH low in the western SBC for experiment 1 is strengthened. As the momentum-balance analysis (Fig. 4) shows, the existence of a Point Buchon low is crucial in forcing onshore convergence and stronger coastal jet in the SMB. That the correction is minor in experiment 3a suggests that the SEB wind may be a more appropriate dataset than the coarse-resolution
ECMWF or the 9-km-resolution COAMPS winds. Note that the three wind vectors are very similar, especially COAMPS and SEB. All show equatorward wind (Fig. 2a). The differences are subtle, especially in their curls near the coast (Fig. 2b).

In the SBC, the cyclonic cell is enhanced for all three wind experiments with data assimilation. The effects of data assimilation are not as large as those in the SMB, however, because there are only three stations available for assimilation (Fig. 1b).

\section{c. Model-observation comparisons}

Some comparisons of the modeled and observed currents at $z=-5 \mathrm{~m}$ have been presented above (Figs. 3 and 5). In the SMB, observed currents show strong 

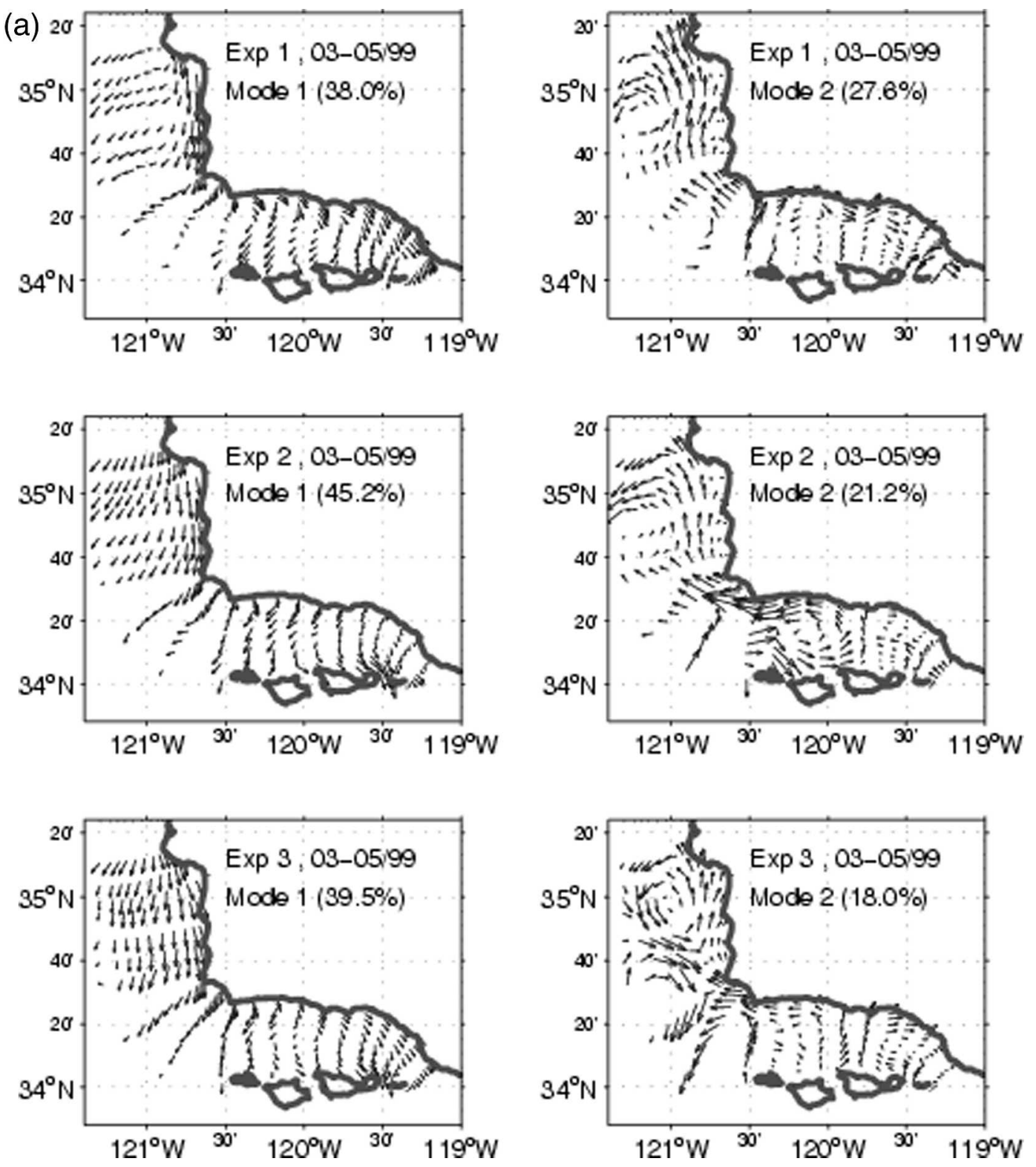

FIG. 9. EOF analysis for the near-surface currents for the wind-only experiments: (top) ECMWF, (middle) COAMPS, and (bottom) SEB. (a) The left panel is the spatial pattern of the first mode, and the right panel shows the second mode; (b) the left panel is the time series of the first mode, and the right panel is for the second mode. The label CC on the left panel denotes the correlation coefficient between the first mode of the surface current and the first mode of the wind stress; the 95\% significance levels are $0.26,0.29$, and 0.25 for expts 1,2 , and 3 , respectively. The $\mathrm{CC}$ on the right panel denotes the correlation coefficient between the second mode of the surface current and the time-integrated first mode of the wind stress curl; the $95 \%$ significance levels are $0.42,0.36$, and 0.39 for expts 1,2 , and 3 , respectively.

alongshore jet (speeds $\approx 0.2 \mathrm{~m} \mathrm{~s}^{-1}$ ). All experiments underestimate the jet, especially at stations inshore, although, as mentioned previously, experiment 3 gives the best overall agreement in that the modeled jet aligns alongshore as is also observed. Assimilation improves the agreements though the modeled currents inshore are still weak. The reason may be that model resolution can become more of an issue for nearshore currents. (The first-mode baroclinic Rossby radius of deformation estimated from climatological data is $\approx 5$ $\mathrm{km}$, comparable to model grid size, though one clearly needs a fraction of this to resolve finescale flow structures; Oey 1998). In the SBC, only three moorings are available for comparison. Observed currents at the two 

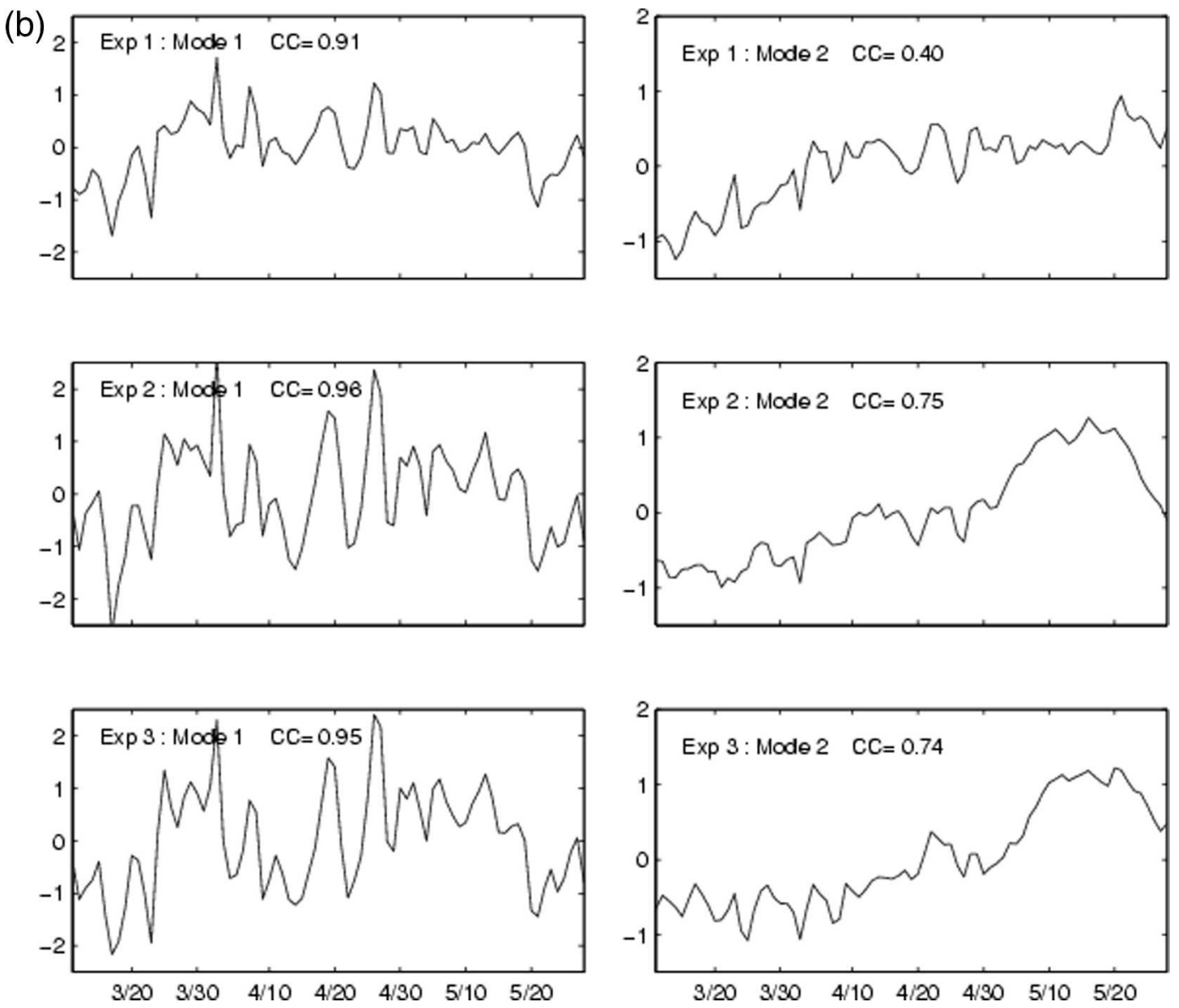

FIG. 9. (Continued)

western stations (SMIN and SMOF) are oppositely directed, indicative of a cyclonic recirculation (Harms and Winant 1998). All experiments also indicate this western cyclone, though experiment 1 with ECMWF is the weakest. Assimilation improves the strength of the cyclone (cf. Oey et al. 2004). At the lone eastern mooring (ANMI), the observed mean is weak. Experiments 1 and 3 both show also weak means (Fig. 3) but for different reasons; the former is because currents in experiment 1 are everywhere generally weak (because of weak ECMWF near-coast), whereas the latter is because the strong SEB wind stress curl is confined to the western SBC (Fig. 2b). By contrast, the COAMPS wind stress curl in experiment 2 extends farther into the channel and modifies the pressure field (Fig. 3b), which allows a stronger poleward flow into the channel (Fig. 3a). Assimilation has relatively minor effects on modeled currents at ANMI (Fig. 5a).

Figure 6 compares current variance ellipses for all experiments. The model generally underestimates variances. Experiment 1 gives the lowest variances, whereas experiment 3 gives better overall agreements with observations, especially in the SMB. There are some improvements for experiments with assimilation (Fig. 6b). Observed currents at ANMI show large fluctuations, which are missing from all of the model experiments. As in Oey et al. (2004), effects of remote forcing (from the south) are not simulated well in the model but are potentially important at ANMI (Auad and Hendershott 1997; Hickey et al. 2003). It is clear that temperature assimilation alone in the channel is insufficient to account for remote forcing. A better way would be to force the model's southern boundary (i.e., off San Diego) with observations (SSH and/or currents) and also to assimilate SSH anomaly from satellite. These options should be investigated in future studies.

\section{EOF analysis}

We further analyze effects of different wind forcing by examining the empirical orthogonal functions of currents, wind, and wind stress curl. In the EOF analysis, the grid points used are further confined to the SMB and SBC. The first modes of wind stresses for ECMWF, 
COAMPS, and SEB are generally directed along-coast (along channel) and explain over $85 \%$ of their variances (Fig. 7). Their time series are similar in phase, but the weather cycles (time scales of about 5-10 days) in COAMPS and SEB are more energetic. The first modes of the wind stress curls explain over $70 \%$ of their variances (Fig. 8). The alongshore patterns are similar to the corresponding wind stress curl maps of Fig. 2b: little variation for ECMWF and cellular structures for COAMPS and SEB. The two organized "cyclonic" structures with maximum EOFs downwind of Points Buchon and Conception are clearly seen in the SEB map. Note that, as will be explained below, the timeintegrated time series of the wind stress curl rather than its time series is shown in Fig. 8.

The EOF analysis of the near-surface currents shows that the first and second modes explain approximately $60 \%$ of the variance (Fig. 9). The first mode (Fig. 9a, left panels) is "unidirectional" and in the SBC resembles the wind-forced upwelling pattern described in Oey et al. (2001). This mode explains nearly $40 \%$ of the total variances. The corresponding time series closely resembles the first mode of wind stress for time scales as short as the "weather" time scales of 5-10 days (cf. Fig. 7); the correlation coefficients exceed 0.90 for all three experiments (1, 2, and 3; Fig. 9b). The high correlation confirms that the first mode of current is primarily driven by along-coast (along channel) wind.

The second mode of the near-surface current shows oppositely directed along-coast flow patterns across the SBC or across the SMB shelf/slope, that is, cyclonic structure. This mode accounts for over $18 \%$ of the variances (Fig. 9a, right panels). The corresponding time series (Fig. 9b, right panels) changes sign near midApril. Thus the inshore flow for this mode changes from equatorward to poleward. The change is small or almost nonexistent for experiment 1 but is significant for experiments 2 and 3 . The sign change indicates the strengthening of the western SBC cyclone from early to late spring (Oey et al. 2004). One might speculate that the strengthening is directly related to wind stress curl (cf. Munchow 2000). However, the correlation between the first-mode wind stress curl and the second mode of surface current is very poor: less than 0.1 . On the other hand, Oey's $(1996,1999)$ analysis shows that the presence of inhomogeneous alongshore wind stress curl can induce nearshore currents and that the relevant forcing function is the time integral of the wind stress curl gradient along the coast, rather than the wind stress curl itself. In the present case, a proxy of this function is simply the time integral of the mode-1 EOF of the wind stress curl. This time-integral function is plotted in Fig. 8 (right panels). For experiment 1 , the correlation be- tween this function and mode- 2 current is weak, $\approx 0.4$. For experiments 2 and 3 , the correlation is high, $\approx 0.74$ (Fig. 9b). The high correlation suggests that the fluctuating nearshore flow (hence also the cyclone) is in part driven by the time integral of the wind stress curl. Comparing Figs. 8 and $9 \mathrm{~b}$, the correlation is due to long period on the order of months. This is consistent with theory (Oey 1999), because the wind curl EOF spans the whole channel (Fig. 8; i.e., scales $\approx 50-100 \mathrm{~km} \gg$ first-mode baroclinic radius of 5-10 km), and the corresponding time scales for significant contribution from the wind stress curl gradient along the coast are $O$ (months).

The existence of poleward inshore flow in the upwelling zone has long been recognized. McCreary et al. (1987) proposed two possible mechanisms: one is induced by the positive wind curl, and the other by the relaxation of the upwelling-favorable wind stress. Oey $(1996,1999)$ suggests that the poleward nearshore current is driven by the poleward pressure gradient, and the gradient is proportional to alongshore gradient of the time-integrated wind stress curl. Wang (1997) showed how a strong poleward alongshore pressure gradient is produced by a positive wind stress curl and drives an inshore poleward current into the upwelling zone. Münchow (2000) found a significant correlation between the wind stress (which is proxy for wind stress curl) and the cyclonic shear observed at the western entrance to the channel using observation data from January to July of 1984. Dever (2004) showed that the velocity potential indicates a source term in the western SBC consistent with the wind stress curl-driven circulation. Here the high correlation between the mode-2 EOF of currents and the time-integrated mode- 1 EOF of the wind stress curl further confirms the relationship between the wind stress curl and the poleward inshore flow. We have confirmed here that the relationship is between the time-cumulated positive wind stress curl and the fluctuating inshore flow.

To explain further how the external force (wind stress curl) drives the inshore poleward flow in the coastal region, we calculate the EOFs of SSH (Fig. 10). The first mode accounts for over $60 \%$ of the total variance and its spatial pattern clearly shows the alongshore pressure gradient. The correlation coefficients between the mode-1 SSH and the mode-1 timeintegrated wind stress curl is 0.58 for experiment 1 and 0.78 for both experiments 2 and 3 . The correlation coefficients between mode- $1 \mathrm{SSH}$ and mode- 2 current are $0.77,0.87$, and 0.75 for experiments $1-3$, respectively. These high correlations reveal that the poleward flow is driven by poleward pressure gradient and that the pressure gradient is set up by the time-integrated wind 

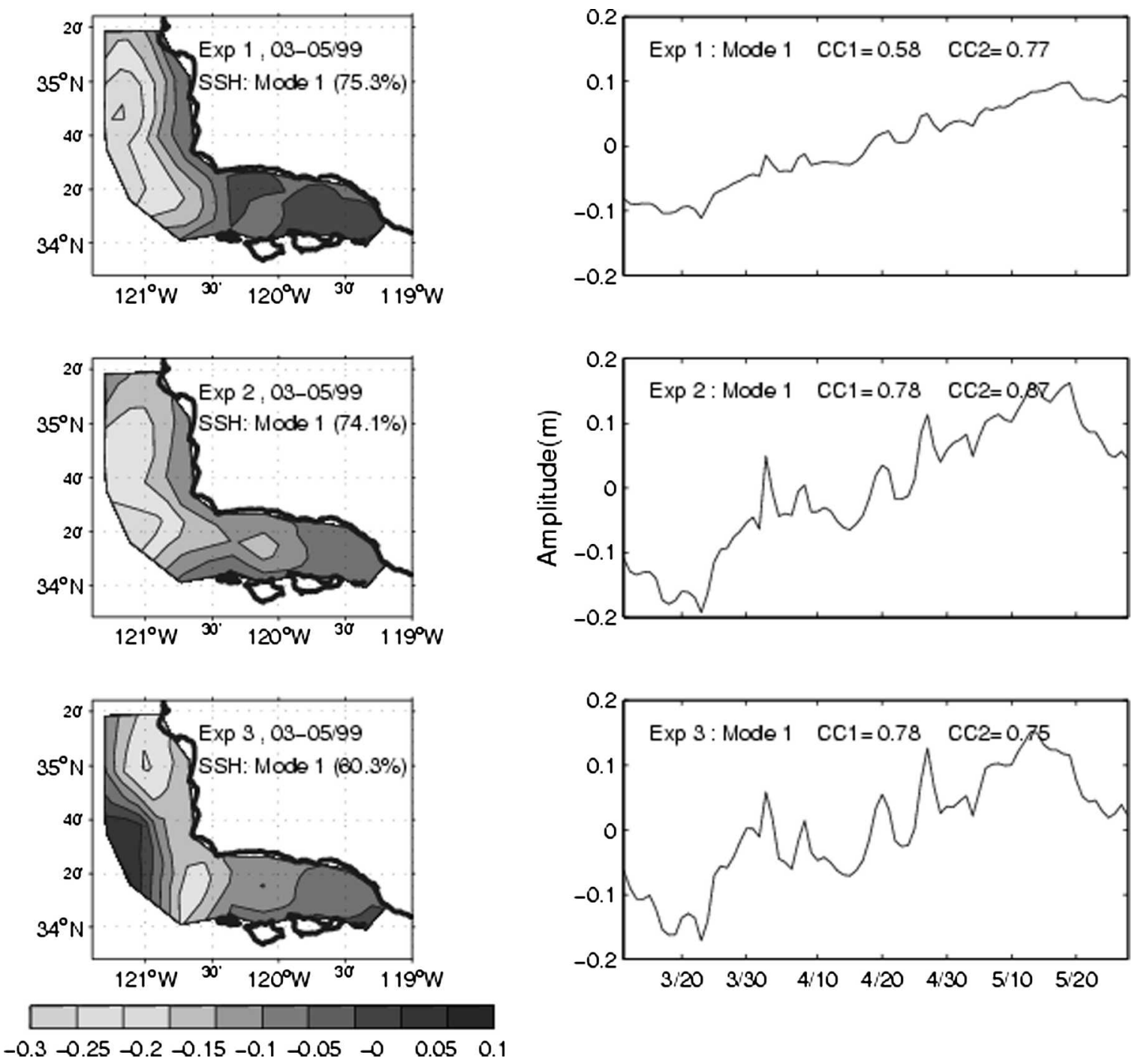

FIG. 10. EOF analysis for the sea surface elevation: (left) the spatial pattern for the first mode and (right) their time series for (top) expt 1, (middle) expt 2, and (bottom) expt 3, respectively. CC1 denotes the correlation between the first mode of the surface elevation and the time-integrated first mode of wind curl; the $95 \%$ significance levels are $0.56,0.44$, and 0.39 for expts 1,2 , and 3 , respectively. $\mathrm{CC} 2$ denotes the correlation between the first mode of the surface elevation and the second mode of the surface current; the $95 \%$ significance levels are $0.56,0.40$, and 0.41 for expts 1,2 , and 3 , respectively.

stress curl. The conclusion agrees with Oey's (1996, 1999) and Wang's (1997) analyses.

\section{Summary}

This paper examines the sensitivity of modeled currents in the SBC and SMB to forcing by three different wind datasets: the ECMWF reanalysis wind; the U.S. Navy's regional model COAMPS wind; and SEB, a wind product that we have derived using satellite SSM/ I, ECMWF, and coastal buoy data. The ECMWF wind has coarse resolution $(\approx 110 \mathrm{~km})$ and is not suitable for circulation modeling in a coastal region that has signifi- cant wind stress and wind stress curl. The resulting modeled currents are weak and are different from observations. Both COAMPS and SEB winds generally produce more energetic currents. In particular, the cyclonic circulation in the western SBC is reproduced well. Subtle differences exist, however, between the two winds, especially in the corresponding wind stress curls. Well-organized local maxima in wind stress curls exist behind capes in the SEB dataset, whereas COAMPS shows a series of cellular wind stress curl patterns along the coast. Alterations to the flow momentum balance are significant. The upshot is a model current field forced by SEB that agrees better with 
observations. EOF analyses show the dominance of two current modes: a mode 1 with unidirectional spatial structure that is forced by the wind and a mode $2 \mathrm{cy}$ clonic spatial structure with poleward inshore flow that is forced by the time integral of the wind stress curl. This latter finding confirms Oey's $(1996,1999)$ and Wang's (1997) analyses.

Acknowledgments. We thank Ed Dever for providing the observational data and Hsiao-Ming Hsu for making the COAMPS data available to us. This work was funded by the Minerals Management Service and the Office of Naval Research. Computing was done at the NOAA GFDL.

\section{REFERENCES}

Auad, G., and M. C. Hendershott, 1997: The low-frequency transport in the Santa Barbara Channel: Description and forcing. Cont. Shelf Res., 17, 779-802.

Chen, C.-S., and D.-P. Wang, 1999: Data assimilation model study of the Santa Barbara Channel. J. Geophys. Res., 104, $15727-$ 15741.

- and - 2000: Data assimilation model study of wind effects in the Santa Barbara Channel. J. Geophys. Res., 105, 22 003-22 013

Daley, R., 1993: Atmospheric Data Analysis. Cambridge University Press, 455 pp.

Dever, E. P., 2004: Objective maps of near-surface flow states near Point Conception, California. J. Phys. Oceanogr., 34, 444-461.

Dong, C. M., L.-Y. Oey, and H. Zhang, 2003: Synthetic winds for the central and southern California coastal ocean. Princeton University AOS Program Rep. 2003-01-02, 23 pp.

Dorman, C. E., and C. D. Winant, 2000: The structure and variability of the marine atmosphere around the Santa Barbara Channel. Mon. Wea. Rev., 128, 261-282.

Harms, S., and C. D. Winant, 1998: Characteristic patterns of the circulation in the Santa Barbara Channel. J. Geophys. Res., 103, 3041-3065.
Hickey, B. M., E. L. Dobbins, and S. E. Allen, 2003: Local and remote forcing of currents and temperature in the central Southern California Bight. J. Geophys. Res., 108, 3081, doi:10.1029/2000JC000313.

Levitus, S., 1982: Climatological Atlas of the World Ocean. NOAA Prof. Paper 13, 173 pp. and 17 microfiche.

_ 1994: World Ocean Atlas 1994 CD-ROM sets. National Oceanographic Data Center Informal Rep. 13.

McCreary, J. P., P. K. Kundu, and S. Y. Chao, 1987: On the dynamics of the California Current System. J. Mar. Res., 45, $1-32$.

Mellor, G. L., 2002: User's guide. [Available online at http:// www.aos.princeton.edu/WWWPUBLIC/htdocs.pom.]

Münchow, A., 2000: Wind stress curl forcing of the coastal ocean near Point Conception, California. J. Phys. Oceanogr., 30, $1265-1280$.

Oey, L.-Y., 1996: Flow around a coastal bend: A model of the Santa Barbara Channel eddy. J. Geophys. Res., 101, $16667-$ 16682.

- 1998: Eddy energetics in the Faroe-Shetland Channel. Cont. Shelf Res., 17, 1929-1944.

— 1999: A forcing mechanism for the poleward flow off the southern California coast. J. Geophys. Res., 104, 13 52913539.

- D.-P. Wang, T. Hayward, C. Winant, and M. Hendershott, 2001: Upwelling and cyclonic regimes of the near-surface circulation in the Santa Barbara Channel. J. Geophys. Res., 106, 9213-9222.

- C. Winant, E. Dever, W. Johnson, and D.-P. Wang, 2004: A model of the near-surface circulation of the Santa Barbara Channel: Comparison with observations and dynamical interpretations. J. Phys. Oceanogr., 34, 23-43.

Wang, D.-P., 1997: Effects of small-scale wind on coastal upwelling with application to Point Conception. J. Geophys. Res., 102, 15 555-15 566.

Winant, C. D., and C. E. Dorman, 1997: Seasonal patterns of surface wind stress and heat flux over the Southern California Bight. J. Geophys. Res., 102, 5641-5653.

_ E. P. Dever and M. C. Hendershott, 2003: Characteristic patterns of shelf circulation at the boundary between central and southern California. J. Geophys. Res., 108, 3021, doi:10.1029/2001JC001302. 